\title{
Improving Port Terminal Operations through Information Sharing
}

\author{
Peter Bjerg Olesen*, Iskra Dukovska-Popovska, and Hans-Henrik Hvolby \\ Centre for Logistics, Department of Mechanical and Manufacturing Engineering, \\ Aalborg University, Denmark \\ pbo@m-tech.aau.dk
}

\begin{abstract}
In modern industry there are well defined methods for planning and optimising the efficiency of the production. However, when looking at supply chain operations there are often problems with lack of communication and planning between nodes. By not communicating the risk of creating non-value adding work also increases as the organisations becomes less synchronised. Therefore the focus in this paper is on how information can improve the performance of a container terminal. It was found that information relating to the containers is currently not widely used. Further it was found that there are improvements to be found in terms of reducing non-value adding activities by utilising information sharing.
\end{abstract}

Keywords: Terminal operations, information sharing, waste, throughput time, case study.

\section{Introduction}

Businesses are becoming increasingly globalized, where each activity in the supply chain is located where the greatest value is added to the final product, which leads to increased transportation and more complex logistics. Since 1990 the global freight volume has almost doubled ([1], [2]). There is now a new growing trend towards greening of the supply chains, in order to lower the carbon footprint, which increases the use of ships as a transport mode, compared to trucks.

Typically supply chain management often focuses on customers and suppliers and not so much on how the goods are transported, and what the logistic performance is between the supply chain nodes, such as trucks, ships, trains, airplanes, shipping ports, truck terminals, airports etc. Due to the increased complexity, there is a need to focus on improving the logistic performance of the supply chain, and thereby reduce the time and cost transporting can impose.

Ports are an integral part of many supply chains, and are increasingly changing their role from being gateways, to becoming active players in the supply chain. Containers are a standardised method for handling cargo, and presents possibilities for

\footnotetext{
* Corresponding author. 
standardising and optimising the processes within a terminal, reducing lead-time and work load. This has enabled a faster transport lead-time which then again has increased the demand for more containers and have put pressure on the supply chains and terminals, leading to an even stronger need to improve operations [2].

This change in supply chains has led to more complex transport routes, where containers often pass several transport hubs, typically going from Asia to e.g. Rotterdam and distributed further into Europe by either ship or truck. Each time a container goes through a transport hub it is subjected to a series of operations, moved from one transport type to another or to storage, e.g. waiting for a specific transport vessel with a specific destination. So in order to increase the competitiveness of the supply chain going through a specific transport hub, it is necessary to optimise the operations, reducing the lead time inside the hub as much as possible. Wang et al [3] have made an extensive analysis of port efficiency, and concludes it is far from optimal, implying the potential for optimisation is large.

This paper will focus on improving the terminal operations by reducing waste and lead-time in a container terminal through information sharing and coordination. In doing this the paper have introduced the general issues regarding port's roles in the global supply chain. Following is a description of how a terminal operates to provide a context. A case study is then introduced to support the arguments that information sharing is not widely applied and that it can have large benefits.

\section{$2 \quad$ Optimising Terminal Operations}

The development of ports has gone from ports just being gateways, to becoming active players in the supply chain. Beresford et al [4] reviews port development and conclude that ports need to be proactive to challenges rather that reactive, which in terms of terminal production can be faster and better customer service, by providing customers with precise information relevant to them. Ports are generally subject to incremental development going towards more integrated systems, supported by ICT. A central part of the operations taking place in a port is the movement of goods from one transport mode to another, this is called terminal operations.

A generic operation setup of a container terminal can be seen in Fig. 1 where different operation areas are presented. Stahlbock et al [5] have made a literature review that to a wide extend covers how the activities in a container terminal operates and concludes that there is need for more focus on reduction of waste and lead-time.

There are some different approaches in the literature towards optimising ports terminal operations and ports in general. Some focus on strategic development and frameworks, where the key is coordination and integration between the different actors involved with the port operations as well as other ports and transport companies ([7], [8]). These models imply that by improving the external link and cooperation, it is possible to improve the internal performance, as the tasks are done more synchronous in the supply chain. This can be difficult in practice as small ports often do not have much leverage towards the supply chains. 


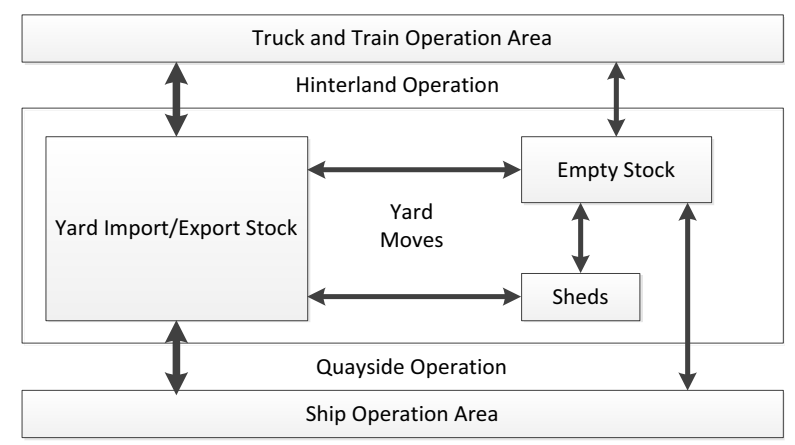

Fig. 1. Illustration of the operations areas in a generic container terminal [6]

The smaller ports can however look at their internal operations to find improvement opportunities. Paixao et al [9] builds a port development framework, based the United Nations Conference on Trade and Development's (UNCTAD's) "Port generations model". More details on UNCTAD can be found in Beresford et al [4]. Paixao et al [9] suggests to improve the operations by transforming the operations through a series of steps, starting with business process reengineering, going through just in time and lean projects ending with an agile and responsive system. Petit et al [10] also suggest the use of lean and agile principles, but segments supply and demand characteristics and attributes to different pipeline strategies, e.g. quick response and continuous replenishment. These frameworks presents an opportunity to use some of the Lean terminology and tools such as waste (muda) and kanban.

Stahlbock et al [5] suggest terminals need a more focussed approach for using ICT to plan the operations, and discuss ICT for supporting planning like seen in traditional "nuts and bolts" production systems. Stahlbock et al [11] further discuss some of the special characteristics in regards to planning and scheduling operations in terminals, such as the uncertainty of incoming containers. This lack of information is also mentioned by Kia et al [12] and Zhou et al [13]. Zhou et al [13] describes how lack of information in a dynamic supply chain reduces efficiency in each level.

The literature however lacks an empirical approach showing how to minimise waste and lead time in container terminals by using information. So this paper will through a case put focus on how information sharing can increase the throughput time of container at a terminal.

\section{Case Study}

The case study is based on a small/medium sized port in Denmark. The port has a wide range of activities with bulk (oil, coal, cereals) and containers as the primary ship arrivals. The port itself is also acting as landlord and infrastructure planner for companies located in the port area. All transport is handled by operators. The focus in this case will be on the container terminal operator. 
The container terminal is divided into three major areas:

- A dedicated area for one container route, segmented between normal and cooling containers.

- A general container storage area for both storage and active storage for other container ship routes.

- A third area divided between specialty cargo, which cannot fit inside a normal container and then empty container storage.

According to Womack et al [14], value adding activities are activities that the customer wants (to pay for) e.g. sending a truck to the terminal, loading, unloading or forwarding goods. Waiting time and unnecessary storage is typically activities which a traditional production company tries to avoid; this line of thinking is imposed in the container terminal to make use of the terminology. Storage can in some cases be value adding, e.g. if a customer wants warehousing services, but this is not part of this papers scope.

\subsection{Physical Flow}

To identify the tasks which are not value adding in a container terminal, it is important to define the concepts in this context.

- Value adding activities

- The activities the customer wants

- Non-value adding activities

- The activities that happens because of lack of planning etc.

- Necessary activities

- Transport and other activities which are impossible to remove but provide no value.

In this terminal the operations looks as follows: A truck arrives and waits for service by the gate and is allowed to move into the terminal and wait for a stacker to take the container. The stacker then moves the container to a storage area. From the storage area the container is picked and put onto a terminal tractor, which in turn drives under the crane that loads it onto the ship. When unloading the ship, the process is almost exactly reverse.

A process flow diagram of the container at the terminal is created in Fig 2 and activities will be analysed from a value adding perspective.

Fig 2 shows waiting time and unnecessary storage of containers that are the main culprits in reducing the lead time and resource utilisation. Also the "rework" that occur when containers are placed so they have to be moved in order to reach other containers, have a significant impact on the resource utilisation.

This amount of rework should as far as possible be avoided by ensuring that knowledge about shipment or pickup of the container is part of the planning. This would allow the operator to stack containers according to when the container is needed. 


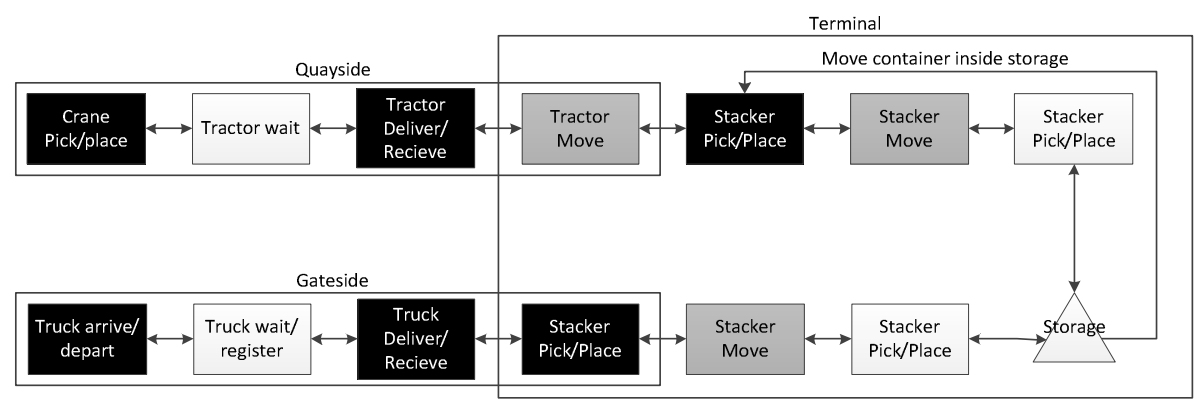

Fig. 2. Shows a simplified container flow in a small container terminal

It is not only the handling of the containers around the storage area that can be a problem. The execution of the processes also poses some pitfalls. The case terminal lists two main issues: making sure the nearest reach stacker picks up a container and making sure the stackers move optimally in relations to container placement. However it has been identified that these two issues are not the main problem at this stage. The question of how to call the nearest stacker is of course very relevant, but in order to do that other things needs to be in place in regards to coordination. With a plan for loading or unloading the ship it would be possible to assign stackers to each lift. Further the problem of storage of containers, according to the case terminal, is that they don't have any information on when a container arrives or when it is picked up, so they do not do anything to optimise this, again a clear lack of information and planning.

As a lack of information is the main reason for not making a good plan (and thereby reducing waiting time, storage, rework etc.) we will look more into the information flow in the terminal.

\subsection{Information Flow}

The information flow is limited today. The terminal operator only communicates on a strategic and operational level with its partners, leaving the tactical information unavailable and unused. Because of this it is not possible to coordinate the operational information to create more optimal sequences of activities. The three planning horizons; strategic, tactical and operational are based on the MPC model from Vollmann et al [15].

Instead, the information flow is directly related to the physical flow, except that execution of orders sometimes is initiated by the gate function. Containers are prior to arrival not known by the terminal, and all activities are dependent on the freight letter, that follows the container. Neither destination nor time information is available before arrival. This adds further to the possibility of lead-time delays, as there is very little coordination. Further arrival/departure time and destination of the container remains an unknown until the ship arrives and the manifest calls the container.

Another problem in terms of not having a plan or schedule for the arrival of trucks from the hinterland is that these trucks risks waiting and that the resource utilisation 
of the terminal can be low. This can be amplified as most trucks tend to arrive around the latest deadline, creating queues and heavy peak hours.

There is access to information about containers arriving via ship, but his information is not used, except for the ships arrival date and the number of containers. Further there is no information on containers going to or from the hinterland, except that the terminal knows that the day before ship departure the terminal is busy serving trucks.

By establishing a coordinating gate function it will be possible to put the available information to use. As the gate could allow slot times for trucks picking up or delivering containers depending on the availability on a container or the capacity of the terminal. This would also allow for planning of container placement in the storage area, reducing the amount of rework done to move containers to get to a specific one. This would be a huge improvement to the current setup.

\section{$4 \quad$ Results and Discussion}

It has been found in the case study, that the lack of planning and information flow is a large contributor to non-value adding activities in the terminal.

A proposal is made in order to improve the use of available information. To improve the information flow, three actions are suggested:

- Registration of containers prior to arrival

- Destination and time information

- Time slots for trucks

- Placement of containers according to time and destination

Registration of time and destination is done in order to know where and when the container is leaving the terminal and also when they arrive. Time slots for trucks should be given prior to trucks arriving at the terminal, in order to ensure the trucks are serviced at once when arriving. And having more information about containers and their destination would allow the terminal to prepare a container for pickup by the arriving truck if the truck has to deliver a new shipment. To improve the terminal operations further the placement of the container in the storage area should be done according to departure and destination and not as now only by owner of the container. By placing the containers according to a schedule, the amount of rework and nonvalue adding activities would be reduced. In general it can be said about the three suggestions that they reduce some of the most obvious non-value adding activities, but in general just presenting the concept of identifying activities as being value or non-value will bring a new positive way of thinking to the terminal.

Even more important is the fact that time slots and more information would allow the terminal to level their production. As it is now the terminal has some very busy rush hours 24 hours before a ships departure. This is because there is no regulation of the input of trucks for the terminal, and then transporters tend to wait until the last minute to deliver the cargo. With time slots, this would definite become more level. 


\section{Practical implications}

This paper's practical implications include showing how available information can be used at terminal operations in order to reduce the waste and improve the throughput of the container.

\section{Research limitations/implications}

The study has limitations and left questions unanswered. The findings are based on one port, and not all the findings can be generalized. The research implications are by offering an empirical case on improving efficiency by utilization of information in small ports.

Future research would include testing the hypothesis of this paper and implement the three suggestions. Also a deeper look into the operations at the terminal, to see if visual management would contribute to improving the control and execution of tasks.

\section{References}

1. United Nations Conference on Trade and Development. Secretariat: Review of maritime transport 2010. United Nations, New York (2010)

2. Notteboom, T., Rodrigue, J.-P.: Containerisation, Box Logistics and Global Supply Chains: The Integration of Ports and Liner Shipping Networks. Maritime Economics \& Logistics 10, 152-174 (2008)

3. Wang, T.-F., Cullinane, K.: The Efficiency of European Container Terminals and Implications for Supply Chain Management. Maritime Economics \& Logistics 8, 82-99 (2006)

4. Beresford, A.K.C., Gardner, B.M., Pettit, S.J., Naniopoulos, A., Wooldridge, C.F.: The UNCTAD and WORKPORT models of port development: evolution or revolution? Maritime Policy \& Management 31, 93-107 (2004)

5. Stahlbock, R., Voß, S.: Operations research at container terminals: a literature update. OR Spectrum 30, 1-52 (2007)

6. Günther, H.-O., Kim, K.-H.: Container terminals and terminal operations. OR Spectrum 28, 437-445 (2006)

7. Brooks, M.R., McCalla, R.J., Pallis, A.A., Van der Lugt, L.M.: Coordination and Cooperation in Strategic Port Management: The Case of Atlantic Canada's Ports. Work 902, 494-1825 (2010)

8. Bichou, K., Gray, R.: A logistics and supply chain management approach to port performance measurement. Maritime Policy \& Management: The Flagship Journal of International Shipping and Port Research 31, 47 (2004)

9. Paixão, A.C., Marlow, P.B.: Fourth generation ports - a question of agility? International Journal of Physical Distribution \& Logistics Management 33, 355-376 (2003)

10. Pettit, S.J., Beresford, A.K.C.: Port development: from gateways to logistics hubs. Maritime Policy \& Management: The Flagship Journal of International Shipping and Port Research 36, 253 (2009)

11. Stahlbock, R., Voß, S.: Vehicle Routing Problems and Container Terminal Operations An Update of Research. In: Golden, B., Raghavan, S., Wasil, E., Sharda, R., Voß, S. (eds.) The Vehicle Routing Problem: Latest Advances and New Challenges, pp. 551-589. Springer, US (2008) 
12. Kia, M., Shayan, E., Ghotb, F.: The importance of information technology in port terminal operations. International Journal of Physical Distribution \& Logistics Management 30, 331-344 (2000)

13. Zhou, H., Benton Jr., W.C.: Supply chain practice and information sharing. Journal of Operations Management 25, 1348-1365 (2007)

14. Womack, J.P., Jones, D.T.: Lean thinking: banish waste and create wealth in your corporation. Simon and Schuster (2003)

15. Vollmann, T.E., Berry, W.L., Whybark, D.C., Jacobs, F.R.: Manufacturing Planning and Control Systems for Supply Chain Management: The Definitive Guide for Professionals. McGraw-Hill Professional (2004) 